\title{
Vaccination Complication, CTCAE
}

National Cancer Institute

\section{Source}

National Cancer Institute. Vaccination Complication, CT CAE. NCI Thesaurus. Code C143216.

A disorder that occurs after the injection of a substance with antig enic properties, administered to activate the immune system. 